\title{
PENGKLASIFIKASIAN GENRE MUSIK INDONESIA MENGGUNAKAN CONVOLUTIONAL NEURAL NETWORK
}

\author{
Carl Ray Wairata ${ }^{(1)}$, Ericks Rachmat Swedia ${ }^{(2)}$ dan Margi Cahyanti ${ }^{(3)}$ \\ ${ }^{1,2}$ Teknik Informatika, Fakultas Ilmu komputer dan Teknologi Informasi, Universitas Gunadarma \\ ${ }^{3}$ Sistem Informasi, Fakultas Ilmu komputer dan Teknologi Informasi, Universitas Gunadarma \\ ${ }^{1,2,3} \mathrm{Jl}$. Margonda Raya No.100, Pondok Cina, Depok \\ E-mail : cray@student.gunadarma.ac.id ${ }^{1)}$, erick_rs@staff.gunadarma.ac.id ${ }^{2)}$, margi@ staff.gunadarma.ac.id ${ }^{3)}$
}

\begin{abstract}
ABSTRAK
Pada zaman sekarang sudah terdapat banyak sekali teknologi Artificial Intelligence. Artificial Intelligence sendiri memiliki beberapa sub bab, salah satunya adalah Machine Learning dan Deep Learning merupakan salah sub bab dari Machine Learning itu sendiri. Convolutional Neural network (CNN) adalah salah satu jenis neural network yang biasa digunakan pada data gambar. Pada penelitian ini akan digunakan untuk mengklasifikasikan genre musik dengan cara mengonversi data pada lagu menjadi sebuah gambar yang kita sebut spektogram. Pada penelitian akan mengimplementasikan CNN dalam mengategorikan 3 genre musik di Indonesia yakni; dangdut, Jazz dan Pop. Pada penelitian ini terdapat 100 lagu untuk masing-masing genre sebagai data setnya. Tujuan dari penelitian ini sendiri adalah mengoptimalkan tingkat akurasi dalam pengategorian genre musik menggunakan model CNN. Berdasarkan penelitian yang sudah dilakukan didapatkan bahwa penggunaan 35 epoch memiliki tingkat akurasi yang optimal yakni; tingkat akurasi tes sebesar $81,33 \%$ dan tingkat akurasi validasi sebesar $100 \%$. Implementasi ini diharapkan dapat menentukan kategori dalam musik.
\end{abstract}

Kata Kunci: Convolutional Neural network, Deep Learning, Lagu, Musik

\section{PENDAHULUAN}

Musik dikenal sejak kehadiran manusia modern Homo sapiens yakni sekitar 180.000 hingga 100.000 tahun yang lalu. Tidak ada yang tahu kapan manusia mulai mengenal seni dan musik (Mahganna, 2020). Musik merupakan bunyi yang diterima oleh individu dan berbeda-beda berdasarkan sejarah, lokasi, budaya dan selera individu. Definisi sejati tentang musik juga bermacam-macam di antaranya bahwa musik adalah bunyi/kesan terhadap sesuatu yang ditangkap oleh indera pendengar, musik adalah suatu karya seni dengan segenap unsur pokok dan pendukungnya, dan musik adalah segala bunyi yang dihasilkan secara sengaja oleh seseorang atau oleh kelompok individu yang disajikan sebagai musik. Dari beberapa definisi tersebut, maka musik merupakan segala bunyi yang dihasilkan manusia secara sengaja yang disajikan sebagai musik (Ardipal, 2020).

Deep Learning merupakan cabang ilmu Machine Learning berbasis Jaringan Saraf Tiruan (JST) atau bisa dikatakan sebagai perkembangan dari JST. (Jaringan Saraf Tiruan) terdiri dari berbagai layer dan beberapa neuron pada masing-masing layer. Kedua hal tersebut tidak dapat ditentukan menggunakan aturan yang pasti dan berlaku berbeda-beda pada data yang digunakan.

Dalam Deep Learning, sebuah komputer belajar mengklasifikasi secara langsung dari gambar atau suara. Metode Deep Learning menggunakan CPU dan RAM dalam proses komputasi, dan juga memanfaatkan GPU sehingga proses komputasi data yang besar dapat berlangsung lebih cepat.

Convolutional Neural network (CNN) adalah salah satu jenis neural network yang biasa digunakan pada data gambar atau citra. Pada penelitian ini akan digunakan untuk mengklasifikasikan genre musik dengan cara mengonversi data pada lagu menjadi sebuah suara yang kita sebut spektogram (Lina, 2019). CNN dapat belajar langsung dari citra sehingga mengurangi beban dari pemrograman. $\mathrm{CNN}$ termasuk dalam jenis Deep Neural network karena dalamnya tingkat jaringan dan banyak diimplementasikan dalam data citra. CNN memiliki dua metode; yakni klasifikasi menggunakan feed forward dan tahap pembelajaran menggunakan back propagation. Cara kerja CNN memiliki kesamaan pada MLP, namun dalam CNN setiap neuron ditampilkan dalam bentuk dua dimensi (Triwijoyo, 2019).

Pada penelitian lain yang berjudul "Klasifikasi Genre Lagu dengan Fitur Akustik Menggunakan Metode K-Nearest Neighbor" bertujuan untuk mengukur kedekatan dua buah lagu akan digunakan persamaan normalized cross correlation (NCC) yang menggantikan persamaan penghitungan jarak pada metode K-NN. Penelitian ini menggunakan 5 genre lagu yaitu Electronic, Rock, Jazz, Pop dan Hip Hop, di mana masing-masing genre-nya memiliki 100 lagu. Dari 100 lagu tersebut 70 lagu akan digunakan sebagai data latih dan 30 lagu sebagai data uji. Penelitian ini dilakukan pengujian terhadap 3 Genre lagu yaitu Pop, Jazz dan Dance. 
Diharapkan dari hasil penelitian ini dapat mengklasifikasikan genre musik dengan menggunakan persamaan normalized cross correlation (NCC) yang menggantikan persamaan penghitungan jarak pada metode K-NN yang telah dilakukan oleh beberapa peneliti sebelumnya seperti Nugraha, Atmaja, Ramatryana dengan judul "Simulasi Dan Analisis Klasifikasi Genre Musik Berbasis Fft Dan K-nearest Neighbor" dan Rahmawati, Magdalena, Ramatryana dengan judul "Perbandingan dan analisis $k$-nearest neighbor dan linear discriminant analysis untuk klasifikasi genre musik“.

\section{RUANG LINGKUP}

Ruang lingkup dari penelitian ini adalah membandingkan model $\mathrm{CNN}$ dengan metode dari 2 penelitian sebelumnya dan mengetahui cara untuk mengoptimalkan tingkat akurasi baik pada proses latihan maupun validasi.

Pada penelitian ini peneliti mengimplementasikan model Convolutional Neural network dalam pengklasifikasian 3 genre musik di Indonesia yakni; dangdut, Jazz dan Pop. Data set yang digunakan berjumlah 300 lagu di mana 1 genre-nya mempunyai masing-masing 100 data lagu. Pada proses latihan, terdapat 90 data digunakan untuk data latihan dan 10 data yang akan digunakan untuk data tes. Pada proses validasi 80 data digunakan untuk data latihan dan terdapat 20 data akan digunakan untuk memvalidasi data. Berdasarkan dari penelitian ini menghasilkan nilai akurasi tes dan nilai akurasi validasi dan output yang dihasilkan diharapkan dapat sesuai dengan kebutuhan.

\section{BAHAN DAN METODE}

Pada bagian ini menjelaskan bahan-bahan dan metode apa yang akan digunakan dalam penelitian ini, di antaranya :

\subsection{Musik}

Musik dikenal sejak kehadiran manusia modern Homo sapiens yakni sekitar 180.000 hingga 100.000 tahun yang lalu. Tidak ada yang tahu kapan manusia mulai mengenal seni dan musik (Mahganna, 2020). Musik merupakan bunyi yang diterima oleh individu dan berbeda-beda berdasarkan sejarah, lokasi, budaya dan selera individu. Definisi sejati tentang musik juga bermacam-macam di antaranya bahwa musik adalah bunyi/kesan terhadap sesuatu yang ditangkap oleh indera pendengar, musik adalah suatu karya seni dengan segenap unsur pokok dan pendukungnya, dan musik adalah segala bunyi yang dihasilkan secara sengaja oleh seseorang atau oleh kelompok individu yang disajikan sebagai musik. Dari beberapa definisi tersebut, maka musik merupakan segala bunyi yang dihasilkan manusia secara sengaja yang disajikan sebagai musik (Ardipal, 2020).

\subsection{Deep Learning}

Pemelajaran dalam (bahasa Inggris: Deep Learning) atau sering dikenal dengan istilah pemelajaran struktural mendalam (bahasa Inggris: deep structured learning) atau pemelajaran hierarki (bahasa Inggris: hierarchical learning) adalah salah satu cabang dari ilmu pemelajaran mesin (bahasa Inggris: Machine Learning) yang terdiri algoritme pemodelan abstraksi tingkat tinggi pada data menggunakan sekumpulan fungsi transformasi nonlinear yang ditata berlapis-lapis dan mendalam (Haixiang, 2017).

Deep Learning merupakan cabang ilmu Machine Learning berbasis Jaringan Saraf Tiruan (JST) atau bisa dikatakan sebagai perkembangan dari JST. Dalam Deep Learning, sebuah komputer belajar mengklasifikasi secara langsung dari gambar atau suara. Convolutional Neural network (CNN/ConvNet) (Sena, 2017) adalah salah satu algoritma Deep Learning yang merupakan pengembangan dari Multilayer Perceptron (MPL) (Azizah, 2018) yang dirancang untuk mengolah data dalam bentuk dua dimensi, misalnya gambar atau suara. CNN dapat belajar langsung dari citra sehingga mengurangi beban dari pemrograman. Metode Deep Learning menggunakan CPU dan RAM dalam proses komputasi, dan juga memanfaatkan GPU sehingga proses komputasi data yang besar dapat berlangsung lebih cepat.

\subsection{Supervised Learning}

Teknik supervised learning merupakan teknik yang bisa diterapkan pada pembelajaran mesin yang bisa menerima informasi yang sudah ada pada data dengan memberikan label tertentu. Diharapkan teknik ini bisa memberikan target terhadap output yang dilakukan dengan membandingkan pengalaman belajar di masa lalu.

\subsection{Gambaran Umum}

Klasifikasi 3 genre lagu indonesia menggunakan python 3.8.5 dan dijalankan menggunakan Anaconda Prompt (miniconda3). Pada bagian gambar 1 ini menjelaskan proses dari pengklasifikasian genre lagu menggunakan Deep Learning dengan model CNN. Penelitian ini sendiri terdiri dari 4 tahap yaitu: pengumpulan data, MFCC, CNN dan hasil.

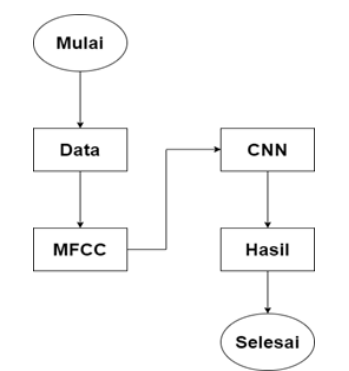

Gambar 1. Alur Sistem 


\subsection{Data Lagu}

Pada Tahapan ini telah diunduh 300 lagu indonesia, di mana 300 lagu-lagu tersebut terbagi menjadi 3 kelompok genre yaitu : Dangdut, Pop dan Jazz. Sebelum dilakukan proses ekstraksi, data format lagu-lagu tersebut harus dikonversi terlebih dahulu menjadi format .wav. Hal ini dilakukan agar python bisa membaca data lagu-lagu tersebut dan melakukan ekstraksi data.

Dari 300 lagu yang sudah diunduh akan dibagi menjadi 2 direktori yakni; direktori latih dan direktori tes dengan perbandingan $90 \%$ untuk direktori latih dan $10 \%$ untuk direktori tes pada tabel 1 .

Tabel 1. Data Lagu

\begin{tabular}{|c|c|c|c|}
\hline Genre & Jumlah Lagu & Latih & Tes \\
\hline Dangdut & 100 & 90 & 10 \\
\hline Jazz & 100 & 90 & 10 \\
\hline Pop & 100 & 90 & 10 \\
\hline
\end{tabular}

\subsection{Mel-Frequency Cepstrum Coefficients}

MFCC adalah representasi yang didefinisikan sebagai nilai real-ceptrum dari short-time signal yang berasal dari spektrogram sinyal suara (Kasih, 2018). Perbedaan dari cepstrum adalah bahwa pada MFCC skala frekuensi nonlinier digunakan, yang mendekati perilaku sistem pendengaran manusia (Gumelar, 2020).

Spektogram sendiri telah berhasil mendapatkan berbagai macam frekuensi yang ada dalam sinyal suara, namun mengikuti struktur koklea pada pendengaran manusia yang menangkap frekuensi pada beberapa titik yang berbeda ditemukan formulasi yang mendekati perilaku sistem pendengaran manusia yang disebut dengan Skala mel (mel-scale) (Nurarinda, 2020).

Skala mel pada dasarnya adalah melakukan filter pada koefisien frekuensi yang didapatkan dari spektogram. Filter yang dilakukan adalah linier pada frekuensi $1000 \mathrm{~Hz}$ dan logaritmik pada frekuensi di atasnya (Tomchuk, 2018) formula (1) digunakan untuk menghitung mel-Frekuensi (Swedia, 2018).

$$
M(f)=2595+\operatorname{LOG}\left(1+\left(\frac{F}{700}\right)\right)
$$

Gelombang suara dari lagu tersebut akan dibuat 13 MFCC agar dapat membentuk matriks. Dimana pada sumbu Y menyatakan MFCC-nya dan sumbu X menyatakan durasi lagu yang ditentukan. Dari setiap blok yang terbentuk memiliki nilai-nilai koefisien. Dari gambar III.4 akan terbentuk 13 x 3000 pixel. Nilai 3000 sendiri ada setiap 1 Blok MFCC memiliki waktu yakni $20 \mathrm{~ms}$, sehingga 1 detiknya terdapat 50 pixel. Dikarenakan lagu berdurasi 60 detik sehingga terdapat 3000 pixels yang dapat dilihat pada 2 gambar (Astuti, 2019).

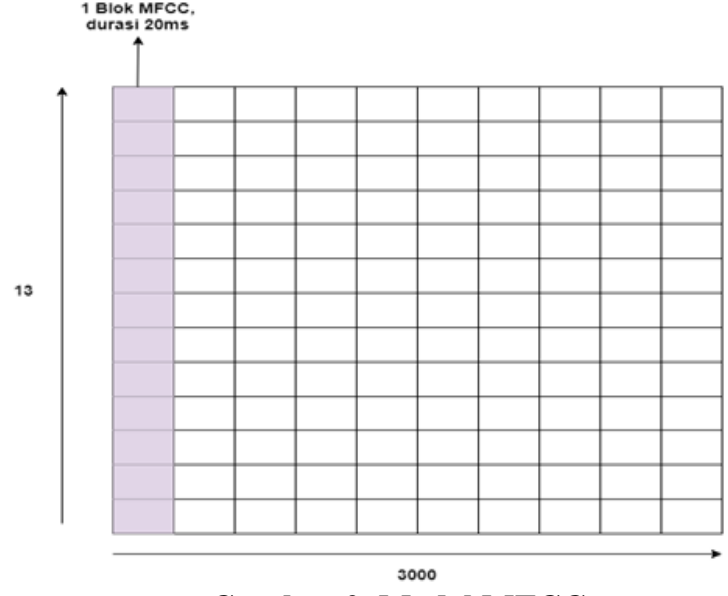

Gambar 2. Model MFCC

Dalam menyimpan data menggunakan modul Json, data akan disimpan dalam sebuah file. Data dari 300 lagu akan disimpan dan dibagi menjadi 3 bagian data yaitu: Mapping, MFCC dan Label.

\subsection{Convolutional Neural network}

Convolutional Neural network adalah salah satu metode Machine Learning dari pengembangan Multi Layer Perceptron (MLP) yang didesain untuk mengolah data dua dimensi. Sebuah perceptron multilayer (MLP) adalah kelas dari feed forward jaringan saraf tiruan (JST). Istilah MLP digunakan secara ambigu, kadangkadang secara longgar untuk setiap JST feed forward, kadang-kadang hanya mengacu pada jaringan yang terdiri dari beberapa lapisan perceptrons (dengan aktivasi ambang). Perceptron multilayer terkadang dalam bahasa sehari-hari disebut sebagai jaringan saraf "vanilla", terutama jika mereka memiliki satu lapisan tersembunyi. CNN terbukti berhasil mengungguli metode Machine Learning lainnya seperti SVM pada kasus klasifikasi objek pada citra. MLP terdiri dari setidaknya tiga lapisan node: lapisan masukan ,lapisan tersembunyi, dan lapisan keluaran . Kecuali node input, setiap node merupakan neuron yang menggunakan fungsi aktivasi nonlinear. MLP menggunakan teknik pembelajaran yang diawasi yang disebut propagative mundur untuk pelatihan. Beberapa lapisan dan aktivasi non-liniernya membedakan MLP dari perceptron linier itu dapat membedakan data yang tidak dapat dipisahkan secara linier (Triwijoyo, 2019).

CNN termasuk dalam jenis Deep Neural network karena dalamnya tingkat jaringan dan banyak diimplementasikan dalam data citra. $\mathrm{CNN}$ memiliki dua metode; yakni klasifikasi menggunakan feed forward dan tahap pembelajaran menggunakan back propagation. Cara kerja CNN memiliki kesamaan pada MLP, namun dalam CNN setiap neuron ditampilkan dalam bentuk dua dimensi (Triwijoyo, 2019).

Konsep CNN ataupun kerja CNN memiliki kesamaan pada MLP, di dalam CNN setiap neuron mempresentasikan dalam bentuk dua dimensi, tidak 
seperti MLP yang setiap neuron hanya berukuran satu dimensi (Darmanto, 2019) seperti gambar 3.

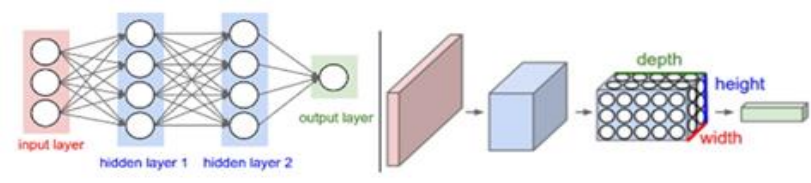

Gambar 3. Alur CNN

Pada CNN, data yang dipropagasikan pada jaringan adalah data dua dimensi, sehingga operasi linier dan parameter bobot pada CNN berbeda. Pada CNN operasi linier menggunakan konvolusi, sedangkan bobot tidak lagi satu dimensi saja, namun berbentuk empat dimensi yang merupakan kumpulan kernel konvolusi. Penelitian ini dibuat 3 model $\mathrm{CNN}$, dimana pada convolutional layer 1, 2 dan 3 menggunakan aktivasi ReLu. Setelah proses CNN selesai akan dilanjutkan ke hidden layer (Abdulbar, 2019). Pada penelitian ini digunakan 64 simpul pada hidden layer. Proses dilanjutkan pada output layer yang berjumlah 3 simpul karena kita mengklasifikasikan 3 genre lagu (Putra, 2020), seperti pada Gambar 4.

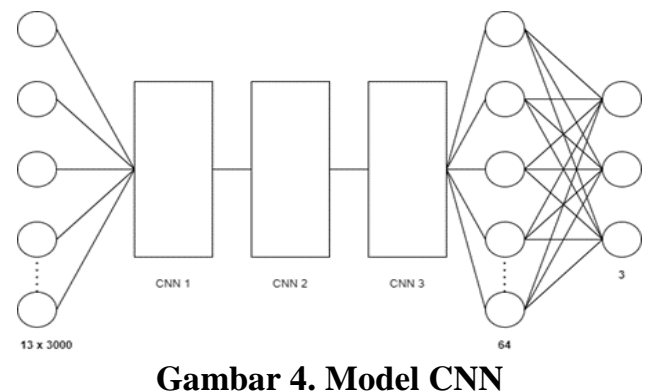

\subsection{Arsitektur Jaringan CNN}

JST (Jaringan Saraf Tiruan) terdiri dari berbagai layer dan beberapa neuron pada masing-masing layer. Kedua hal tersebut tidak dapat ditentukan menggunakan aturan yang pasti dan berlaku berbeda-beda pada data yang digunakan.

Sebuah jaringan tanpa hidden layer dapat memetakan persamaan linier, sedangkan jaringan dengan satu atau dua hidden layer dapat memetakan sebagian besar persamaan pada data yang sederhana. Namun pada data yang lebih kompleks, MLP memiliki kekurangan atau keterbatasan. Pada permasalahan jumlah hidden layer di bawah tiga layer, terdapat pendekatan untuk menentukan jumlah neuron pada masing-masing layer untuk mendekati hasil optimal. Penggunaan layer di atas dua pada umumnya tidak direkomendasikan dikarenakan akan menyebabkan over fitting serta kekuatan back propagation berkurang secara signifikan. Berkembangnya Deep Learning, ditemukan bahwa untuk mengatasi kekurangan MLP dalam menangani kasus data kompleks, diperlukan fungsi untuk mentransformasikan data input menjadi bentuk yang lebih mudah dimengerti oleh MLP. Hal tersebut memicu berkembangnya Deep Learning di mana dalam satu model diberikan beberapa layer untuk melakukan transformasi data sebelum data diolah menggunakan metode klasifikasi. Hal tersebut memicu berkembangnya model neural network dengan jumlah layer di atas tiga. Namun dikarenakan fungsi layer awal sebagai metode ekstraksi fitur, maka jumlah layer dalam sebuah DNN tidak memiliki aturan universal dan berlaku berbeda-beda tergantung dataset yang digunakan. Sebuah CNN terdiri dari beberapa layer. Berdasarkan arsitektur LeNet5, terdapat empat macam layer utama pada sebuah CNN namun yang diterapkan pada TA ini hanya tiga macam lapisan antara lain (Nurhikmat, $\mathrm{T}, 2018$ ) :

1. Convolution Layer

2. Subsampling Layer

3. Fully Connected Layer

\section{PEMBAHASAN}

Tahap MFCC adalah tahap di mana dilakukan ekstraksi data terhadap lagu-lagu yang telah diunduh dan diubah menjadi bentuk numerik atau dalam bentuk matriks lebih tepatnya. Proses ekstraksi data ini menggunakan python dan beberapa modul yang harus diinstal terlebih dahulu yaitu : os, Librosa, Math dan Json. Proses ekstraksi data pada gambar 5.

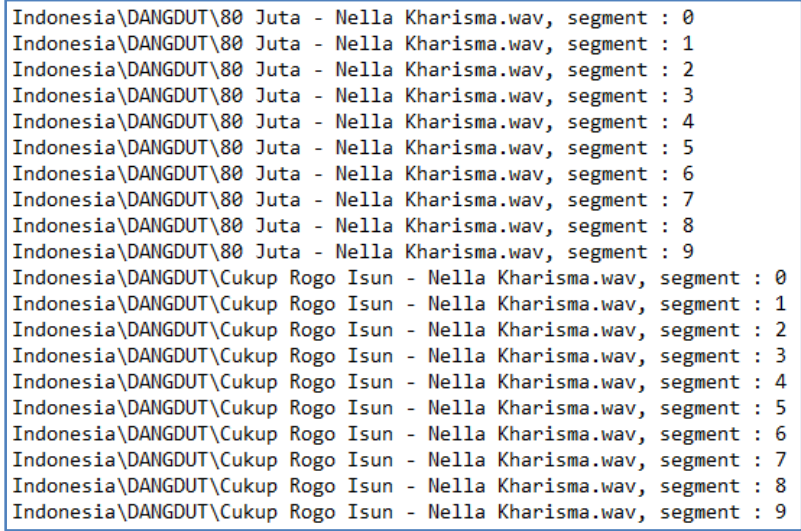

\section{Gambar 5. Ekstraksi Data Lagu}

Setelah proses ekstraksi data selesai dilakukan maka akan menghasilkan Mapping MFCC dan Label pada gambar 6 di mana 1 Blok MFCC memiliki waktu yakni $20 m s$. 


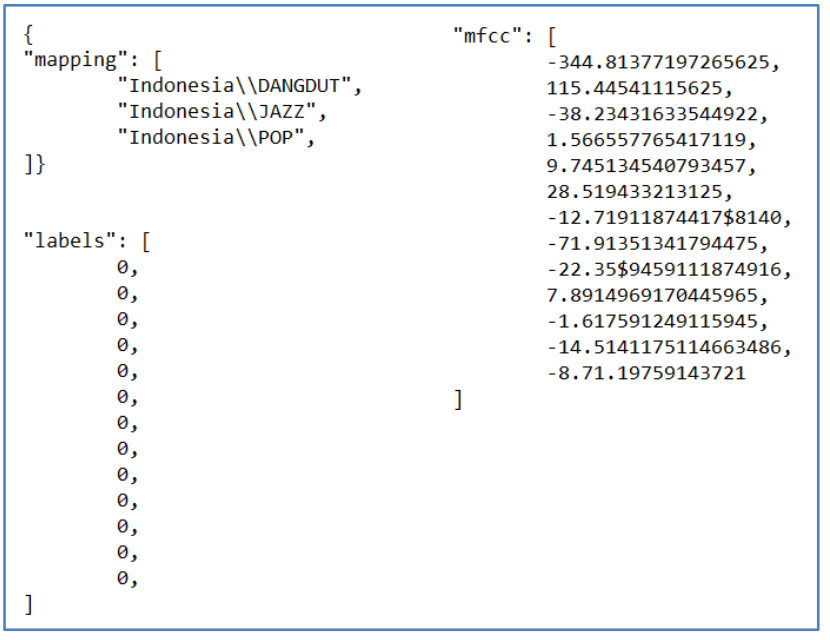

\section{Gambar 6. Mapping, MFCC dan Label}

Pada gambar 7. merupakan contoh proses Deep Learning dengan jumlah epoch sebanyak 15, input data pada indeks 1333 dan targetnya pada indeks 1333. Pada contoh ini didapatkan indeks yang seharusnya didapat adalah indeks 0 (Genre Dangdut) dan indeks yang diprediksi oleh komputer adalah sama yaitu 0 (Genre Dangdut) dengan tingkat akurasi sebesar.

\begin{tabular}{|c|c|}
\hline \multirow{3}{*}{ 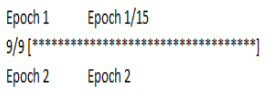 } & \\
\hline & - 054 (ms/step) - loss: 1.5108 - accuracy:0.3926-val_loss: 3.7166 -val_accuracy: 0.2333 \\
\hline & \\
\hline 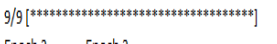 & - 0s 30(ms/step) - loss: 1.2943 - accuracy: 0.46630 - val_loss: 3.6839 - val_accuracy: 0.2000 \\
\hline & \\
\hline $\begin{array}{l}9 / 9[* * * * * * * * * * * * * * * * * * * * * * * * * * * * * * * * * *] \\
\text { Epoch4 Epoch } 4\end{array}$ & - 0s 31(ms/step) - loss: 1.0988 - accuracy: 0.5556 - val_loss: 3.5729 - val_accuracy: 0.2000 \\
\hline 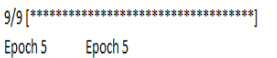 & 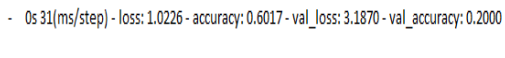 \\
\hline $\begin{array}{l}9 / 9[* * * * * * * * * * * * * * * * * * * * * * * * * * * * * * * * *+] \\
\text { Epoch } 6 \quad \text { Epoch } 6\end{array}$ & - 0s 30 (ms/step) - loss: 0.9137 - accuracy: 0.6748 - val_loss: 2.8399 - val_accuracy: 0.2000 \\
\hline 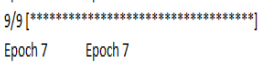 & - 0531 (ms/step) - loss:0.7813 - accuracy: 0.6667-val_loss: 2.5969- val_accuracy: 0.1667 \\
\hline 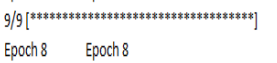 & - 0s 31 (ms//step) - loss: 0.7378 - accuracy; 0.6667 -val_loss: 2.2540 - val_accuracy: 0.1667 \\
\hline $\begin{array}{l}9 / 9[* * * * * * * * * * * * * * * * * * * * * * * * * * * * * * * * *+] \\
\text { Epoch } 9 \quad \text { Epoch } 9\end{array}$ & - 0s 31(ms/step) - loss: 0.6822 - accuracy: 0.7111 - val_loss: 2.1048 - val_accuracy: 0.1667 \\
\hline 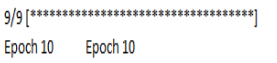 & 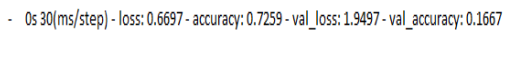 \\
\hline 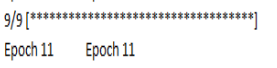 & - 0s 30(ms/step) - loss:0.6169 - accuracy: 0.7407 - val_loss: 1.8422 - val_accuracy: 0.2000 \\
\hline $\begin{array}{l}9 / 9[* * * * * * * * * * * * * * * * * * * * * * * * * * * * * * * * *+] \\
\text { Epoch } 12 \quad \text { Epoch } 12\end{array}$ & - 0s 31 (ms/step) - loss:0.5780 - accuracy: 0.7630 - val_loss: 1.6988 - yal_accuracy: 0.2667 \\
\hline 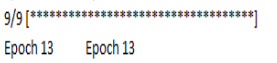 & - 0s 30(ms/step) - loss: 0.5129 - accuracy: 0.7926 - val_loss: 1.5247 - val_accuracy: 0.3333 \\
\hline 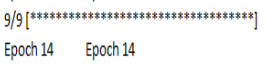 & 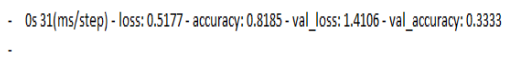 \\
\hline 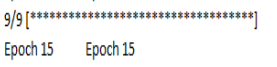 & 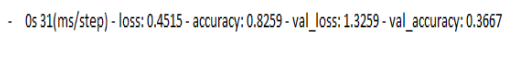 \\
\hline 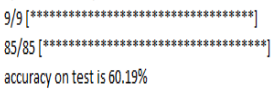 & 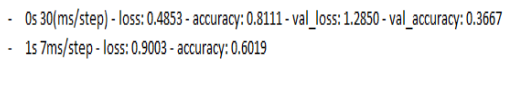 \\
\hline
\end{tabular}

Gambar 7. Proses Deep Learning

Dengan menggunakan Mapping, MFCC dan Label barulah metode $\mathrm{CNN}$ bisa dilakukan Pada penelitian ini akan dilakukan percobaan terhadap 10 array data lagu yang yakni data array pertama sampai dengan kesepuluh dan pada setiap data array tersebut akan dilakukan beberapa kali percobaan untuk melihat tingkat akurasi dan keberhasilan program yang paling efektif berdasarkan jumlah epoch-nya. Penelitian ini indeks 0 merupakan genre lagu dangdut, indeks 1 merupakan genre lagu Jazz dan indeks 2 merupakan genre lagu Pop seperti pada tabel 2 dengan mengujikan beberapa epoch.

Tabel 2. Percobaan 10 sampai 35 Epoch

\begin{tabular}{|c|c|c|c|c|}
\hline Epoch & Data & Expect & Predict & Cocok \\
\hline \multirow{10}{*}{10} & 1 & 2 & 2 & $\checkmark$ \\
\hline & 2 & 2 & 2 & $\checkmark$ \\
\hline & 3 & 2 & 1 & $\mathrm{X}$ \\
\hline & 4 & 2 & 2 & $\checkmark$ \\
\hline & 5 & 1 & 0 & X \\
\hline & 6 & 1 & 2 & $\mathrm{X}$ \\
\hline & 7 & 2 & 1 & $\mathrm{X}$ \\
\hline & 8 & 2 & 2 & $\checkmark$ \\
\hline & 9 & 0 & 0 & $\checkmark$ \\
\hline & 10 & 1 & 0 & $\mathrm{X}$ \\
\hline \multicolumn{4}{|c|}{ Akurasi Validasi } & $50 \%$ \\
\hline \multirow{10}{*}{20} & 1 & 2 & 2 & $\checkmark$ \\
\hline & 2 & 1 & 1 & $\checkmark$ \\
\hline & 3 & 1 & 1 & $\checkmark$ \\
\hline & 4 & 2 & 2 & $\checkmark$ \\
\hline & 5 & 0 & 2 & $\mathrm{X}$ \\
\hline & 6 & 0 & 1 & $\mathrm{X}$ \\
\hline & 7 & 0 & 0 & $\checkmark$ \\
\hline & 8 & 0 & 1 & $\mathrm{X}$ \\
\hline & 9 & 0 & 0 & $\checkmark$ \\
\hline & 10 & 0 & 0 & $\checkmark$ \\
\hline \multicolumn{4}{|c|}{ Akurasi Validasi } & $70 \%$ \\
\hline \multirow{10}{*}{30} & 1 & 2 & 2 & $\checkmark$ \\
\hline & 2 & 2 & 2 & $\checkmark$ \\
\hline & 3 & 1 & 1 & $\checkmark$ \\
\hline & 4 & 1 & 1 & $\checkmark$ \\
\hline & 5 & 1 & 1 & $\checkmark$ \\
\hline & 6 & 1 & 1 & $\checkmark$ \\
\hline & 7 & 1 & 1 & $\checkmark$ \\
\hline & 8 & 2 & 2 & $\checkmark$ \\
\hline & 9 & 2 & 0 & $\mathrm{X}$ \\
\hline & 10 & 0 & 1 & $\mathrm{X}$ \\
\hline \multicolumn{4}{|c|}{ Akurasi Validasi } & $80 \%$ \\
\hline \multirow{10}{*}{35} & 1 & 2 & 2 & $\checkmark$ \\
\hline & 2 & 2 & 2 & $\checkmark$ \\
\hline & 3 & 0 & 0 & $\checkmark$ \\
\hline & 4 & 2 & 2 & $\checkmark$ \\
\hline & 5 & 2 & 2 & $\checkmark$ \\
\hline & 6 & 0 & 0 & $\checkmark$ \\
\hline & 7 & 1 & 1 & $\checkmark$ \\
\hline & 8 & 1 & 1 & $\checkmark$ \\
\hline & 9 & 2 & 2 & $\checkmark$ \\
\hline & 10 & 2 & 2 & $\checkmark$ \\
\hline
\end{tabular}

Berdasarkan percobaan di atas dapat dilihat dari tingkat akurasi validasi paling tinggi pada array data pertama sampai dengan kesepuluh jika menggunakan 35 
epoch. Nilai akurasi validasi dari data array di tabel 2 pertama sampai dengan kesepuluh antara lain, 10 Epoch memiliki nilai akurasi validasi 50\%, 20 Epoch memiliki nilai akurasi validasi $70 \%, 30$ Epoch memiliki nilai akurasi validasi 80\%, 40 Epoch memiliki nilai akurasi validasi $70 \%$, dan 35 epoch memiliki nilai akurasi validasi $100 \%$ (Tabel 6.). Nilai akurasi tes pada epoch 35 sendiri adalah $81.33 \%$. Output dari Tabel penelitian bisa dilihat contohnya terdapat pada gambar 9, sedangkan output nilai akurasi tes dapat di lihat pada gambar 10 dan grafik akurasi validasi berdasarkan jumlah epoch bisa dilihat pada gambar 10 .

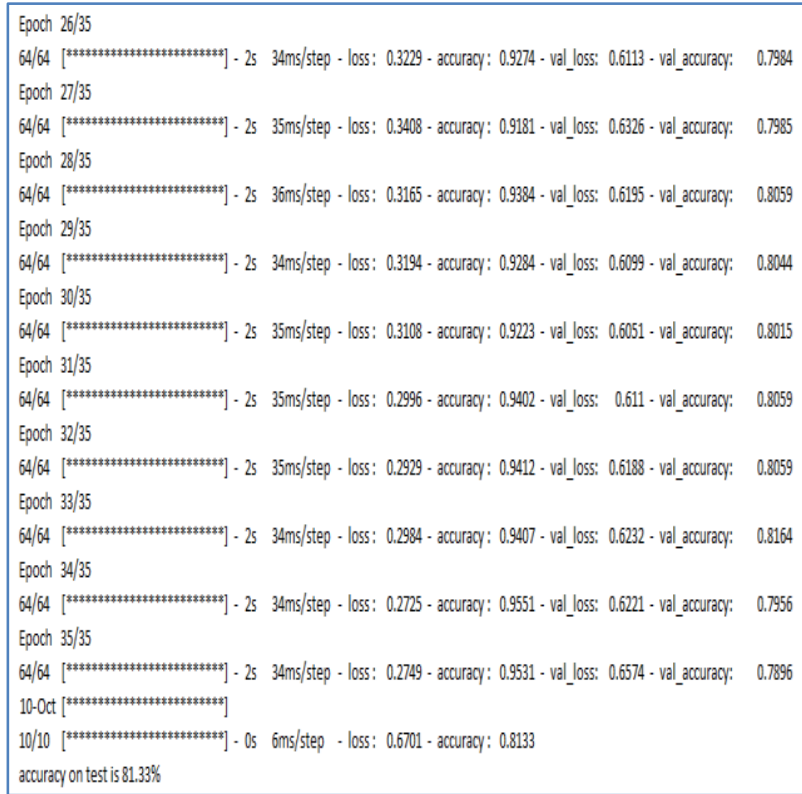

Gambar 9. Nilai Akurasi Tes

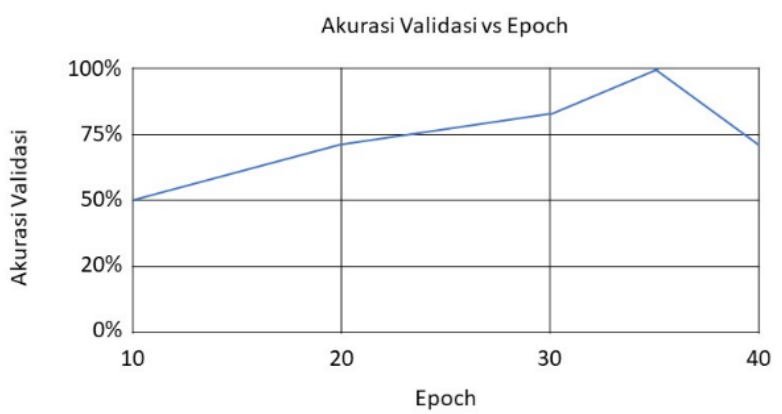

Gambar 10. Grafik Akurasi Validasi

\section{KESIMPULAN}

Model Convolutional Neural network merupakan salah satu metode Machine Learning yang banyak diimplementasikan dalam data citra. Untuk penggunaan CNN dalam data audio, pertama data audio akan diubah menjadi sebuah gambar dengan koordinat $\mathrm{x}$ sebagai Amplitudo dari audio itu sendiri, sedangkan koordinat y sebagai durasi waktu dari audio tersebut. Setelah diubah menjadi gambar maka akan dilakukan proses Deep Learning menggunakan model CNN.
Setelah melakukan percobaan pada data array pertama sampai dengan yang kesepuluh menggunakan 35 epoch merupakan yang paling efektif karena mendapatkan akurasi validasi $100 \%$ dan akurasi tes sebesar $81.33 \%$. Jika dibandingkan dengan penelitian sebelumnya yang menggunakan metode K-Nearest Neighbor yang mendapatkan akurasi sebesar 63\%, maka metode CNN lebih mendapatkan tingkat akurasi yang lebih tinggi. Berbeda dengan penelitian berbasis FFT dan Support Vector Machine, model CNN mendapatkan tingkat akurasi yang sedikit lebih rendah.

\section{SARAN}

Saran untuk penelitian ini adalah ke depannya bisa memperbanyak dataset agar akurasi yang didapatkan lebih baik lagi, dikarenakan pada penelitian ini lagu-lagu yang pada dataset tidak memiliki batas yang jelas antara satu genre dengan genre lainnya. Selain itu diharapkan penelitian ini dapat dikolaborasikan dengan penelitianpenelitian sebelumnya untuk mendapatkan hasil yang lebih baik lagi seperti menguji dengan metode dari Algoritma deep learning lainnya.

\section{DAFTAR PUSTAKA}

Abdulbar, H., Adikara, P. P., \& Adinugroho, S. 2019. Klasifikasi Genre Lagu dengan Fitur Akustik Menggunakan Metode K-Nearest Neighbor. Jurnal Pengembangan Teknologi Informasi dan Ilmu Komputer e-ISSN, 2548, 964X.

Ardipal, A. 2020. Pemanfaatan Perangkat Teknologi dalam Pembelajaran Musik Berbasis Tematik sebagai Peningkatan Keterampilan Abad 21 Bagi Guru Sekolah Dasar. Musikolastika: Jurnal Pertunjukan Dan Pendidikan Musik, 2(2), 77-84.

Astuti, D. 2019. Aplikasi Identifikasi Suara Hewan Menggunakan Metode Mel-Frequency Cepstral Coefficients (MFCC). Journal of Informatics, Information System, Software Engineering and Applications (INISTA), 1(2), 26-34

Azizah, L. M., Umayah, S. F., \& Fajar, F. 2018. Deteksi Kecacatan Permukaan Buah Manggis Menggunakan Metode Deep Learning dengan Konvolusi Multilayer. Semesta Teknika, 21(2), 230-236.

Darmanto, H. (2019). Pengenalan Spesies Ikan Berdasarkan Kontur Otolith Menggunakan Convolutional Neural network. Joined Journal (Journal of Informatics Education), 2(1), 41-59.

Gumelar, A. B., Yuniarno, E. M., Anggraeni, W., Sugiarto, I., Kristanto, A. A., \& Purnomo, M. H. 2020. Kombinasi Fitur Multispektrum Hilbert dan Cochleagram untuk Identifikasi Emosi Wicara. Jurnal Nasional Teknik Elektro dan Teknologi Informasi, 9(2), 180-189.

Haixiang, G., Yijing, L., Shang, J., Mingyun, G., Yuanyue, H., \& Bing, G. 2017. Learning from classimbalanced data: Review of methods and 
applications. Expert Systems with Applications, 73, 220-239.

Kasih, P. 2018. Voice Recognition untuk Sistem Keamanan PC Menggunakan Metode MFCC dan DTW. Generation Journal, Department Of Informastics Engineering, 2(1), 57-68.

Lina, Qolbiyatul. 2019. Apa itu Convolutional Neural network?. https://medium.com/@16611110/apa-ituconvolutional-neural-network-836f70b193a4 (diakses pada tanggal 6 Januari 2021).

Mahganna, S. 2020. OLIOREANG: Entitas Ritmis dan Melodi Mandar (Vol. 1). Gerbang Visual.

Nurarinda, T. A. P., Sahertian, J., \& Mahdiyah, U. 2020. Rancangan Sistem Identifikasi Jenis Burung Kicau Berdasarkan Suara Burung dengan Mel Frequency Cepstrum Coefficiens (MFCC). In Seminar Nasional Inovasi Teknologi e-ISSN (Vol. 2549, No. 7952, p. 7952).

Nurhikmat, T. 2018. Implementasi Deep Learning Untuk Image Classification Menggunakan Algoritma Convolutional Neural network (CNN) Pada Citra Wayang Golek.

Putra PN, C. S. 2020. Deteksi Penyakit Tanaman Padi Dengan Menggunakan Convolutional Neural network (Doctoral dissertation, UPN Veteran Jawa Timur)

Sena, S. 2017. Pengenalan Deep Learning Part 7 Convolutional Neural network CNN. https://medium.com/@samuelsena/pengenalandeep-learning-part-7-convolutional-neural-networkcnn-b003b477dc94 (Diakses pada 12 April 2021).

Swedia, E. R., Mutiara, A. B., \& Subali, M. 2018. Deep learning long-short term memory (LSTM) for Indonesian speech digit recognition using LPC and MFCC Feature. In 2018 Third International Conference on Informatics and Computing (ICIC) (pp. 1-5). IEEE.

Triwijoyo, B. K. 2019. Model Fast Tansfer Learning pada Jaringan Syaraf Tiruan Konvolusional untuk Klasifikasi Gender Berdasarkan Citra Wajah. MATRIK: Jurnal Manajemen, Teknik Informatika dan Rekayasa Komputer, 18(2), 211-221.

Tomchuk, K. K. 2018. Spectral Masking in MFCC Calculation for Noisy Speech. In 2018 Wave Electronics and its Application in Information and Telecommunication Systems (WECONF) (pp. 1-4). IEEE. 